Supplement of Hydrol. Earth Syst. Sci., 23, 2841-2862, 2019

https://doi.org/10.5194/hess-23-2841-2019-supplement

(c) Author(s) 2019. This work is distributed under

the Creative Commons Attribution 4.0 License.

(c) (1)

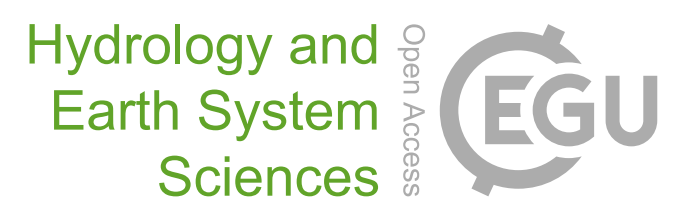

Supplement of

\title{
Multi-decadal hydrologic change and variability in the Amazon River basin: understanding terrestrial water storage variations and drought char- acteristics
}

\section{Suyog Chaudhari et al.}

Correspondence to: Yadu Pokhrel (ypokhrel@egr.msu.edu)

The copyright of individual parts of the supplement might differ from the CC BY 4.0 License. 


\section{LHF Model and Setup}

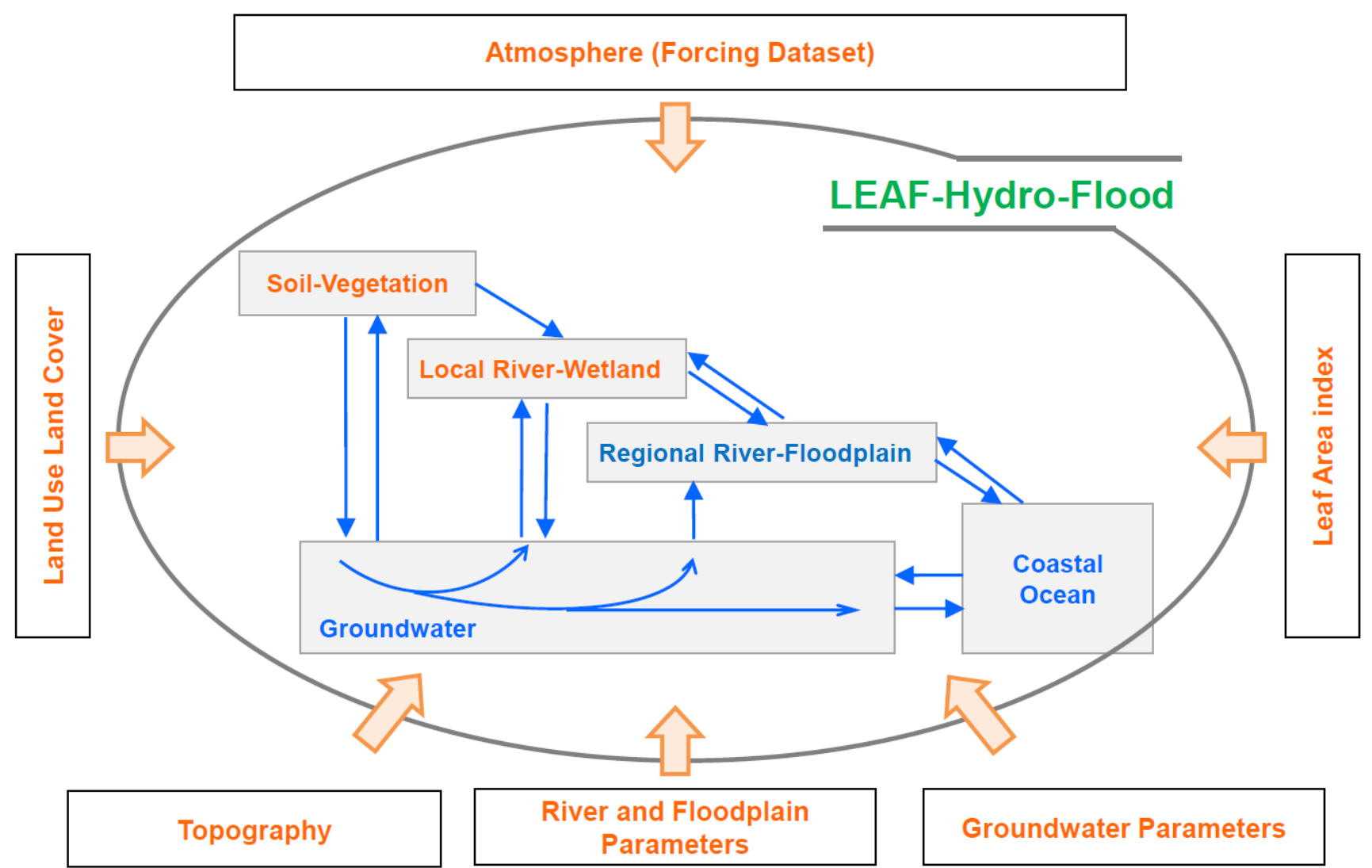

Figure S1 - Stores and fluxes included in LEAF-Hydro-Flood (LHF) model along with its overall structure and inputs. This flowchart is modified after Miguez-Macho and Fan, (2012). 


\section{Validation of Simulated streamflow with Observations}

Figure S2 show the locations of the streamflow gauge stations for which the data was acquired from Agência Nacional de Águas (ANA) in Brazil (http:// hidroweb.ana.gov.br). Selection of stations are made with respect to the length of the data available, with minimum data gaps, and their location in the basin.

5 Figure S3 compares the simulated streamflow with observed streamflow acquired from ANA at 12 main stations in the Amazon River basin (locations are indicated in Figure S2). Seasonal dynamics for both simulated and observed streamflow for each streamflow station are also shown in the right panel of each subplot. Trend and the comparison statistics are indicated in each subplot. Note that the y-axis values are expressed exponentially.

Figure S4 compares the observed and simulated streamflow with climatology removed at 12 main streamflow stations. Shaded

10 areas indicate the seasonal minimums and maximums for both observed and simulated streamflow values. The model successfully captures the transitions from the climatological mean compared to observed transitions. Maximum and minimum monthly variations are also well apprehended by the model. Although the model operates adeptly in varying geographical regions, the uncertainties carried from the forcing input are evident from the comparison with observed values. Given that none of the model parameters are calibrated or altered, it can be concluded that the interannual and climatological biases found

15 in the model results are directly carried over from the forcing input (see section 3.2). 


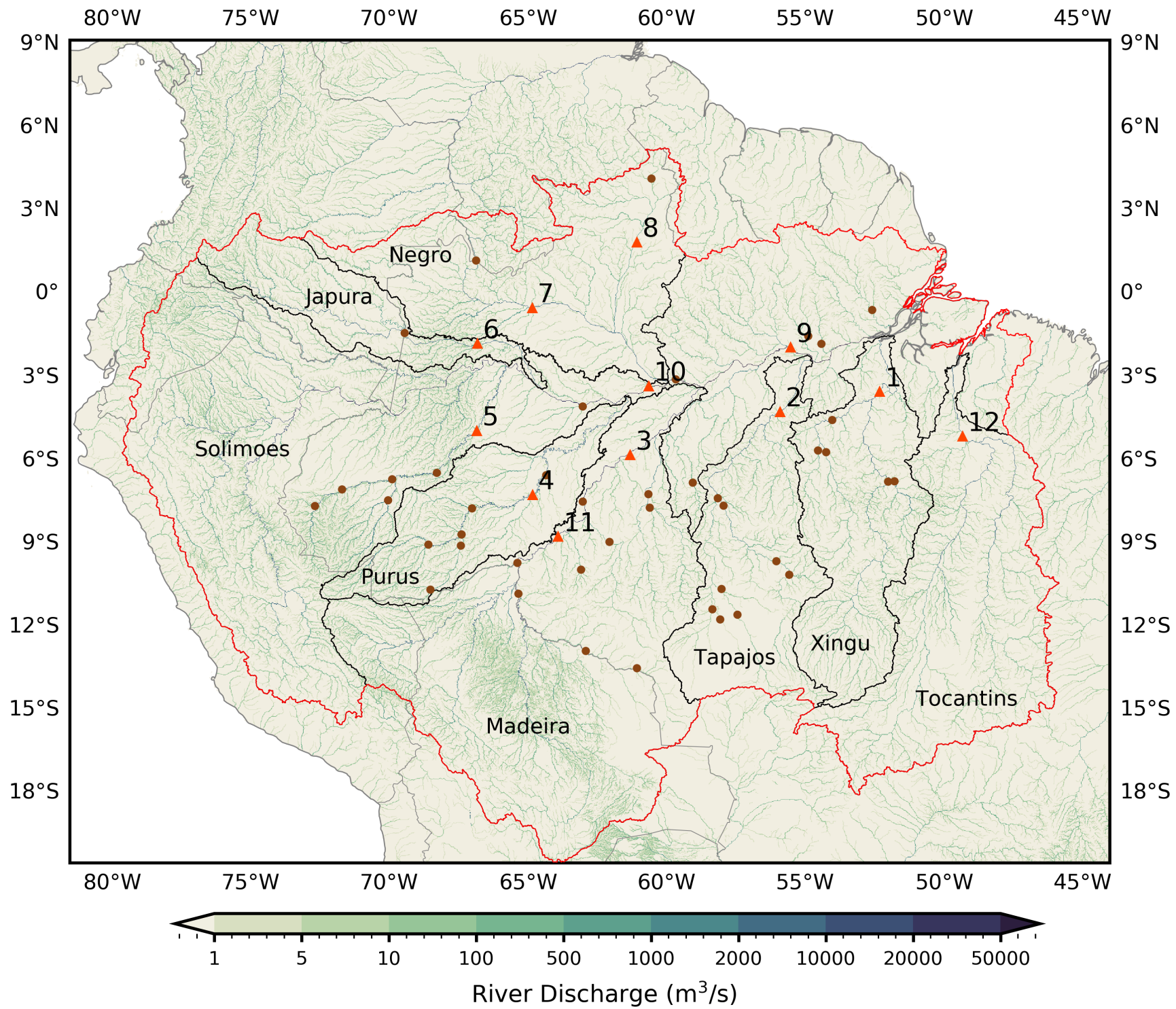

Figure S2 - Spatial distribution of simulated streamflow from LHF at the original $\sim 2$ km model grids. Markers indicate the locations of the stream gauge stations we use to validate the simulated streamflow from LHF. Highlighted and indexed markers are the gauge stations for which a timeseries comparisons are shown in Supplementary Figure S2. Red line shows the extend of Amazon River 5 basin including the Tocantins region. 

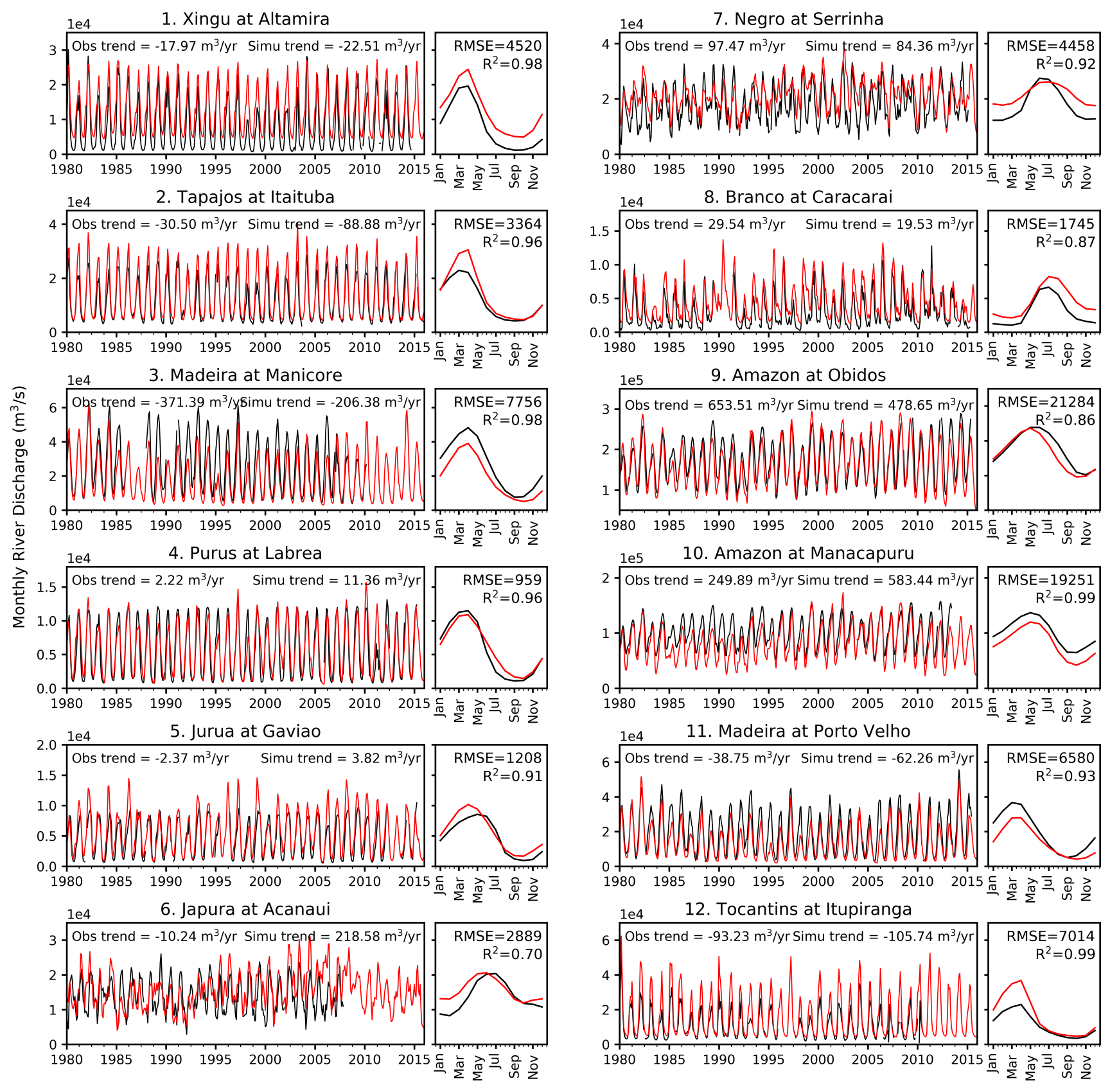

Figure S3 - Comparison of observed streamflow (black) obtained from ANA Brazil and simulated streamflow (red) from LHF at 12 main gauge stations. Seasonal cycle for each station is also shown in the right panel of each subplot. The locations of the streamflow gauge stations are indicated in Figure S1. 

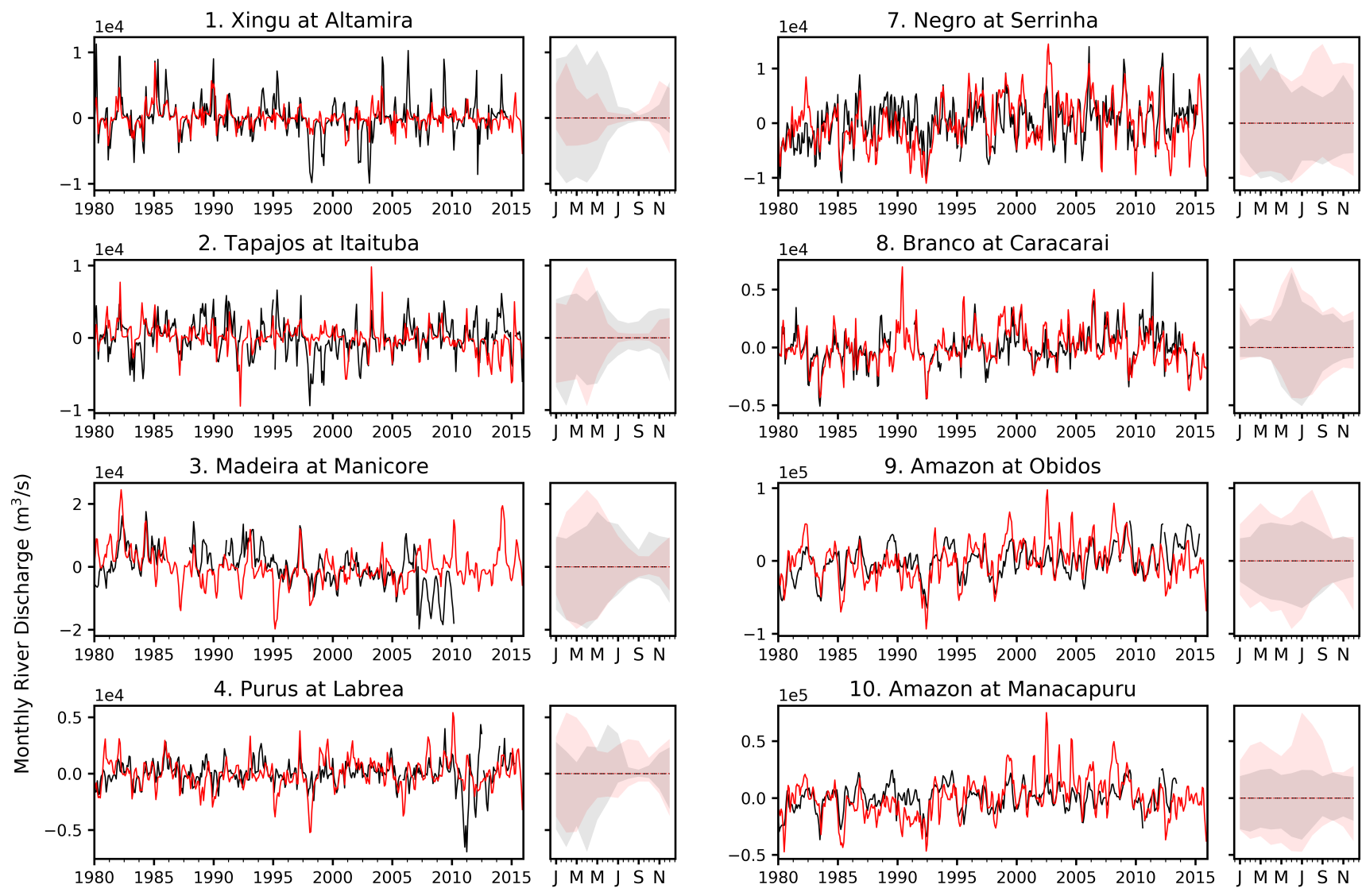

1e5 10. Amazon at Manacapuru
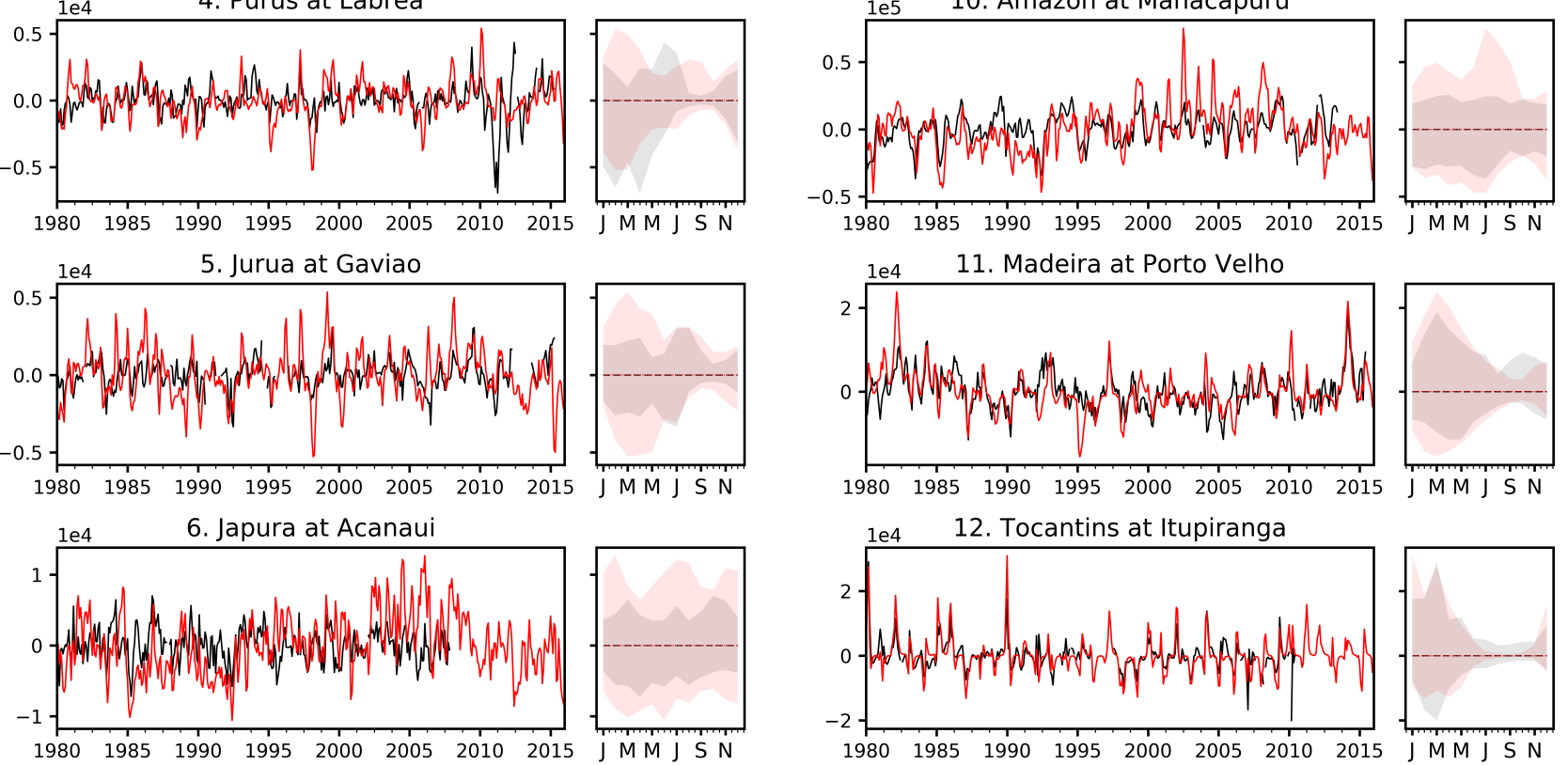

Figure S4 - Comparison of observed streamflow (black) and simulated streamflow (red) with climatology removed at 12 main gauge stations along with the mean seasonal cycle. The shaded area represents the seasonal minimum and maximum observed (black) and simulated (red) streamflow. 


\section{Trends in Forcing Precipitation and Temperature}

Figure S5 displays temporal trends in the input precipitation and temperature from WFDEI dataset, we use to drive the LHF model. Grids with significant trend at 99\% level are highlighted with markers.
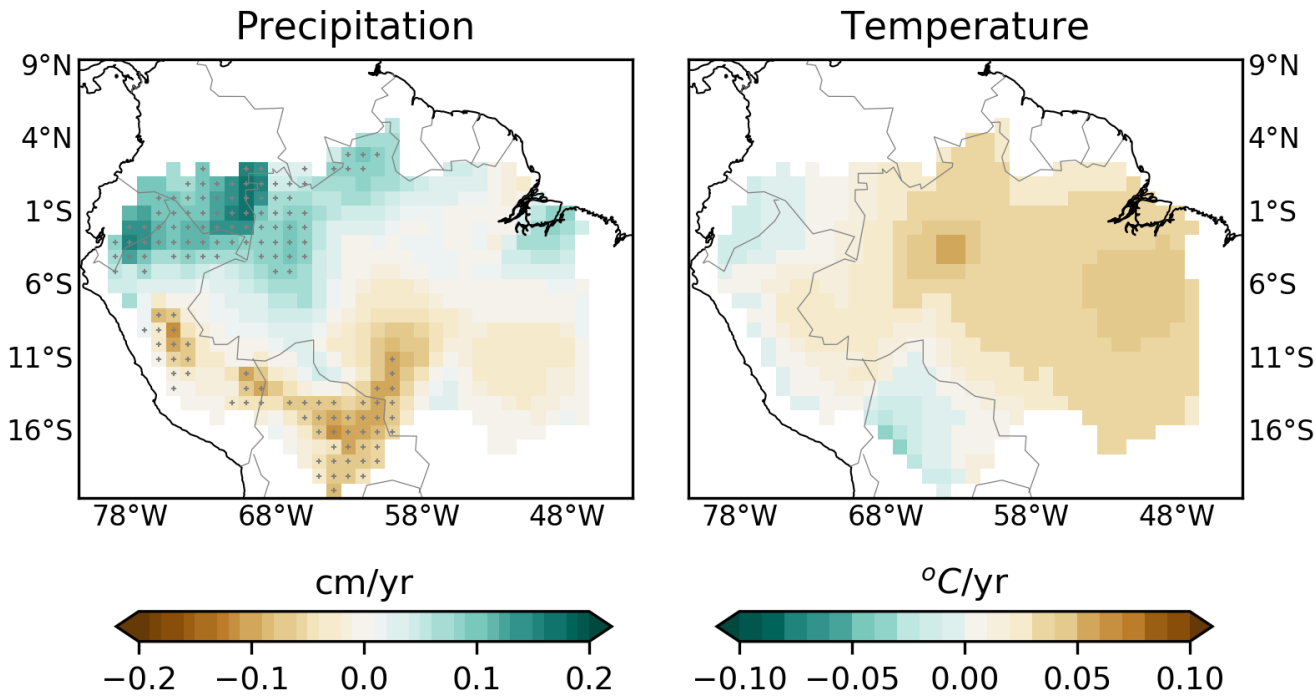

5 Figure S5 - Temporal trend in precipitation and temperature obtained from WFDEI forcing dataset for the simulation period (i.e. 1980-2015). Markers indicate significant trends at $99 \%$ level. 


\section{Comparison of Simulated TWS anomalies with GRACE}

Figure S6 presents temporal trends in input precipitation form WFDEI during the GRACE period, i.e. 2002-2015. The trends are calculated for anomalies at $0.5^{\circ} \times 0.5^{\circ}$ resolution. The uncertainty with decreasing precipitation trend evident over the Andes is carried over to the model results causing slight discrepancies between simulated TWS and GRACE anomalies. All the trends

5 are expressed in $\mathrm{cm} /$ year.

Figure S7 presents the comparison of GRACE and simulated TWS anomalies with climatology removed for 2002-2015 period along with their seasonal minimums and maximums. This result contributes a crucial insight in the ongoing heated discussion regarding the mismatch between GRACE and model TWS trends (Scanlon et al., 2018; Sun et al., 2019). Note only the mean of GRACE mascon products from JPL and GFZ centres is used in this comparison.
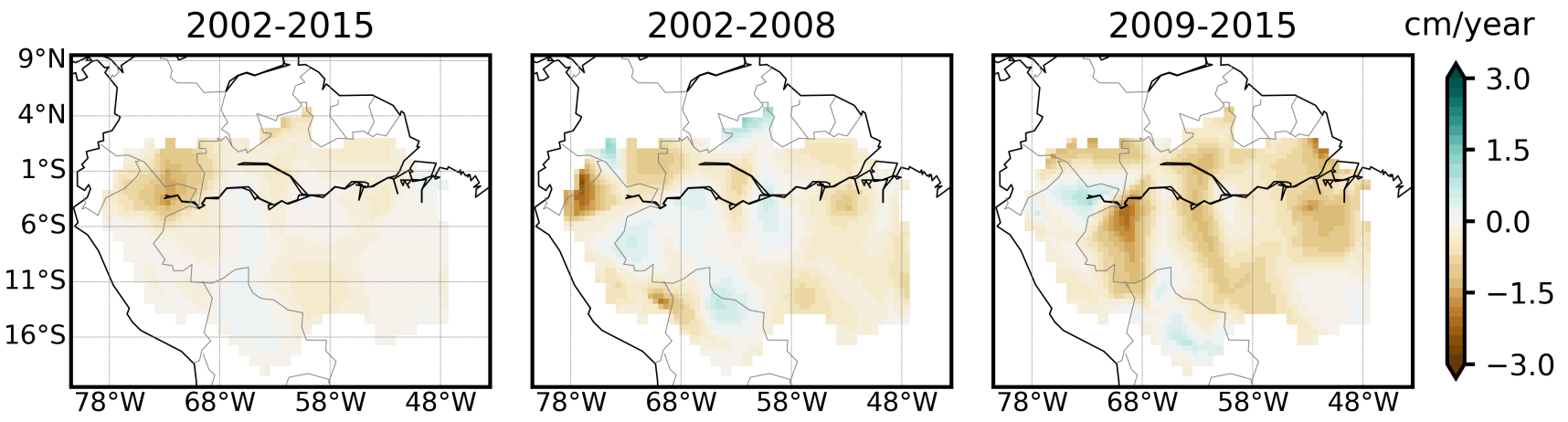

Figure S6 - Temporal trend in precipitation obtained from WFDEI forcing dataset for the model-GRACE overlap period (i.e. 20022015). Note that the entire model-GRACE overlap period was split in two timeframes for further analysis (see Section 4.3). 
GRACE vS TWS comparison with climatology removed
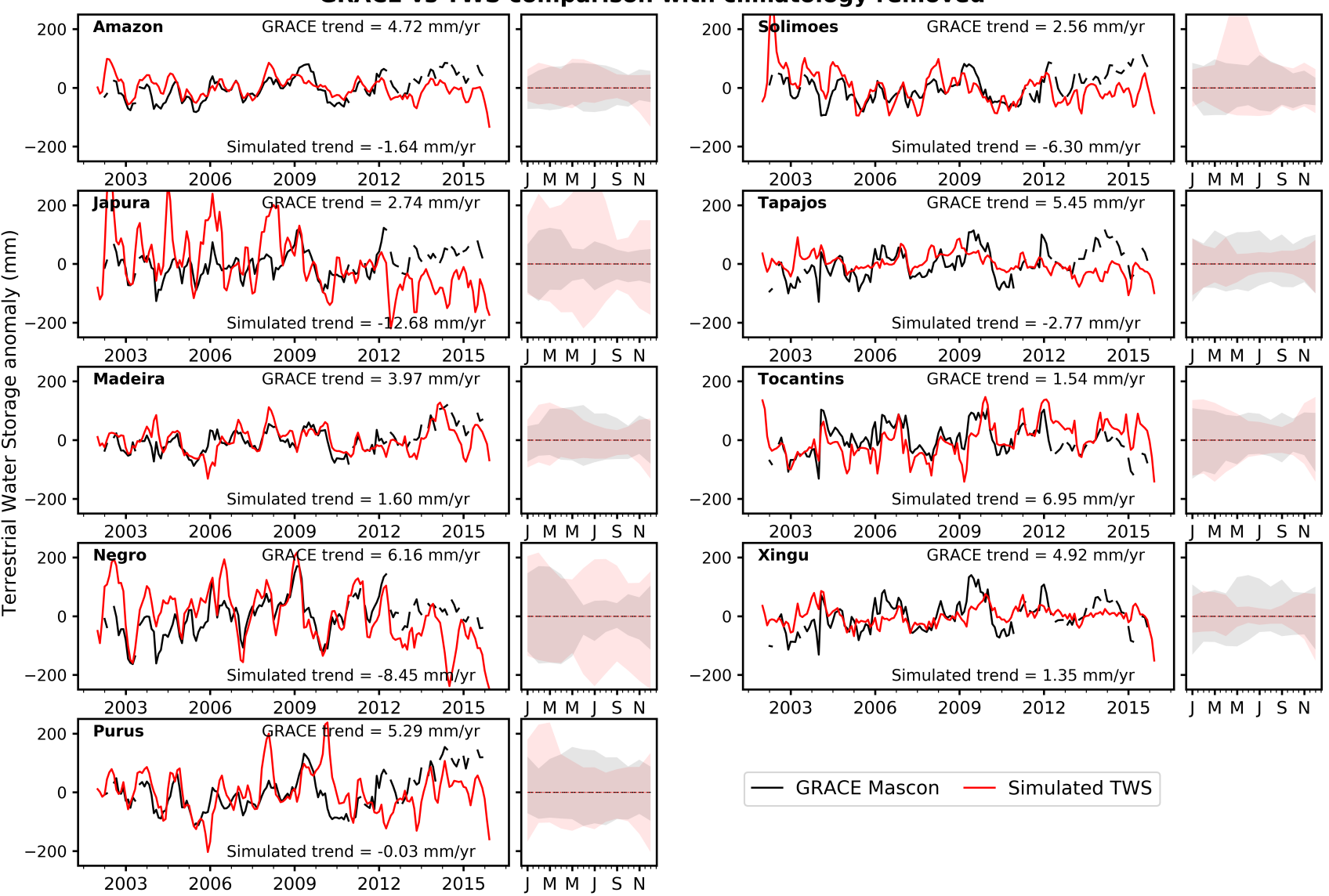

Figure S7 - Comparison of GRACE and simulated TWS anomalies with climatology removed for Amazon and its sub-basins. Shaded areas in the right panel of each subplot indicate the seasonal mean of GRACE (red) and TWS from LHF (black). Temporal trends in GRACE and simulated TWS anomalies are also indicated in each subplot. 
Land Use Land Cover (LULC) dynamics from ESA-CCI Land Cover product

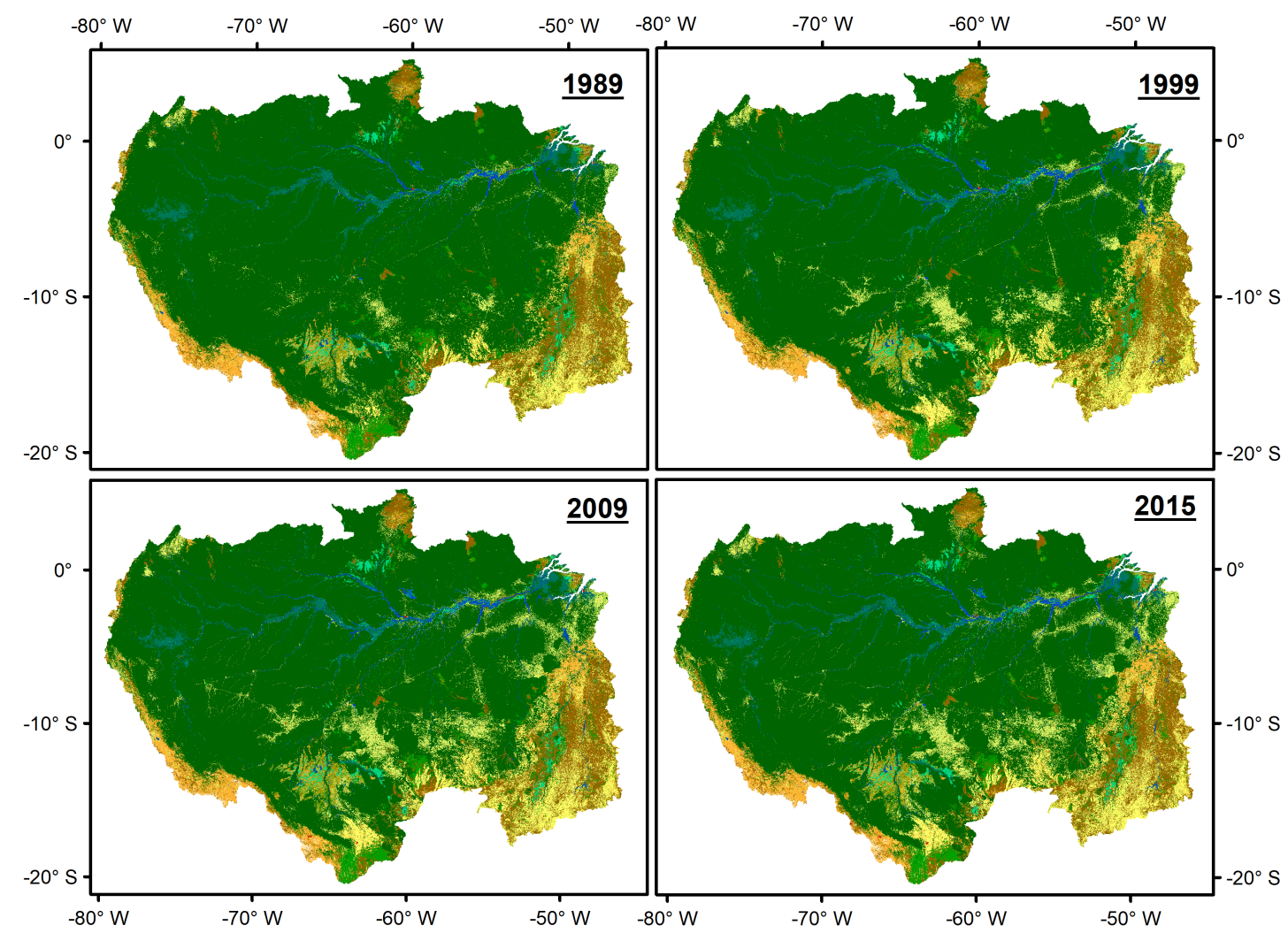

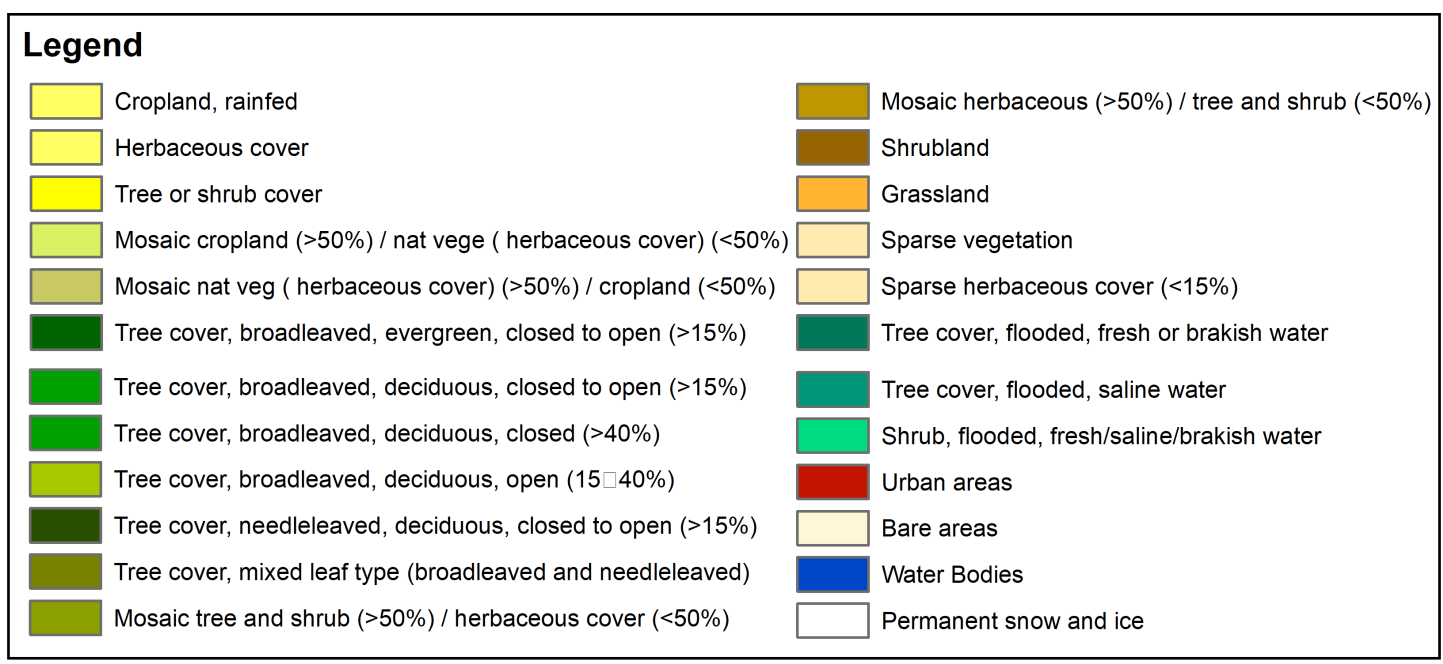

Figure S8 - LULC maps obtained from ESA-CCI Land Cover product at the end of each decade from 1980-2010 and 2015 representing the on-going decade at $\sim 2 \mathrm{~km}$ resolution. Original data is available as annual maps from $1992-2015$ at $300 \mathrm{~m}$ resolution.

5 The 1989 LULC map is derived using a pixel-by-pixel analysis explained in Section 2.4 of the paper. Original data is aggregated to $\sim 2 \mathrm{~km}$ for model runs. 


\section{Interannual and Interdecadal Simulated TWS Anomalies, Trends and Changes}

The monthly and annual variations in TWS and their respective trends are shown in Figure S9 for the entire study period. Subbasins undergoing large LULC changes are experiencing negative TWS trends, for example, Madeira (-1.41 mm/y), Tapajos $(-1.96 \mathrm{~mm} / \mathrm{y})$, Tocantins $(-3.13 \mathrm{~mm} / \mathrm{y})$ and Xingu (-1.91 mm/y). Although the entire Amazon river basin is becoming wetter 5 over the years $(1.13 \mathrm{~mm} / \mathrm{y})$, the southern and south-eastern regions of the basin are getting drier rapidly.
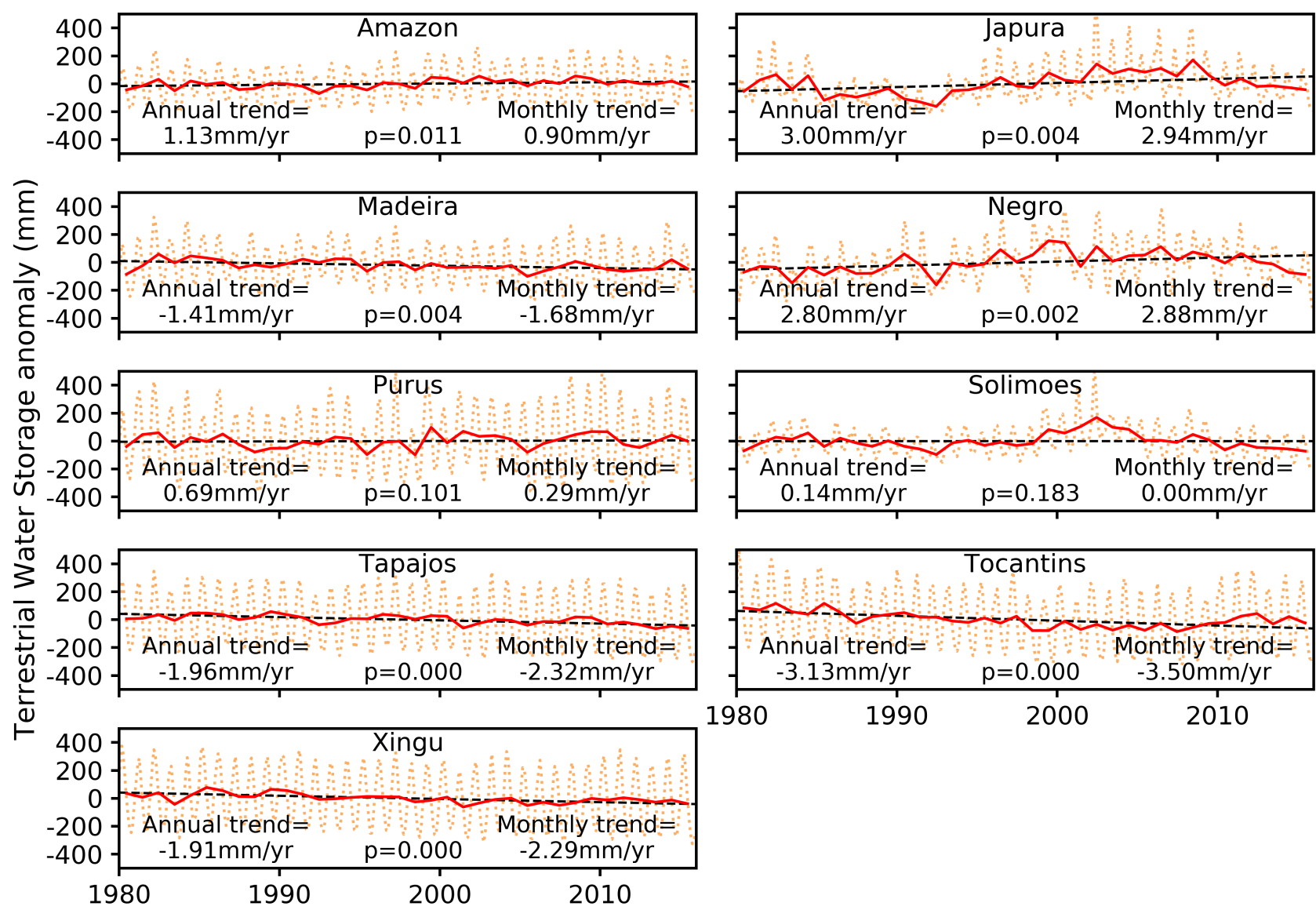

Figure S9 - Timeseries of monthly and annual basin averaged TWS anomalies for Amazon and its sub-basins. The p values were calculated for the annual trend using Mann-Kendall trend test which indicate the significance of the trends at $99 \%$ level. 
Table S1 - Significance of Interdecadal TWS differences in Amazon basin and its sub-basins. Mean and standard deviations (STD) of monthly TWS timeseries of individual decades are also shown. The significance is calculated using a t-test methodology.

\begin{tabular}{|c|c|c|c|c|c|c|c|c|c|}
\hline Basin & Period & Mean & STD & $\begin{array}{l}\text { Statistical } \\
\text { Significance }\end{array}$ & Basin & Period & Mean & STD & $\begin{array}{l}\text { Statistical } \\
\text { Significance }\end{array}$ \\
\hline \multirow{4}{*}{ Amazon } & $1980 \mathrm{~s}$ & -12.1 & 108.0 & No & \multirow{4}{*}{ Solimoes } & $1980 \mathrm{~s}$ & -5.6 & 76.6 & No \\
\hline & $1990 \mathrm{~s}$ & -14.4 & 111.4 & Significant & & $1990 \mathrm{~s}$ & -20.7 & 86.6 & Significant \\
\hline & $2000 \mathrm{~s}$ & 24.7 & 123.2 & No & & $2000 \mathrm{~s}$ & 56.8 & 118.9 & Significant \\
\hline & $2010 \mathrm{~s}$ & 3.1 & 129.7 & & & $2010 \mathrm{~s}$ & -50.9 & 82.7 & \\
\hline \multirow{4}{*}{ Japura } & $1980 \mathrm{~s}$ & -33.3 & 100.4 & No & \multirow{4}{*}{ Tapajos } & $1980 \mathrm{~s}$ & 24.1 & 169.2 & No \\
\hline & 1990s & -43.0 & 110.3 & Significant & & $1990 \mathrm{~s}$ & 9.4 & 171.5 & No \\
\hline & $2000 \mathrm{~s}$ & 84.1 & 147.2 & Significant & & $2000 \mathrm{~s}$ & -10.9 & 180.2 & No \\
\hline & $2010 \mathrm{~s}$ & -7.7 & 90.1 & & & $2010 \mathrm{~s}$ & -43.7 & 184.5 & \\
\hline \multirow{4}{*}{ Madeira } & $1980 \mathrm{~s}$ & -4.9 & 138.9 & No & \multirow{4}{*}{ Tocantins } & $1980 \mathrm{~s}$ & 53.8 & 185.1 & Significant \\
\hline & $1990 \mathrm{~s}$ & -5.8 & 122.9 & Significant & & $1990 \mathrm{~s}$ & -11.9 & 179.9 & No \\
\hline & $2000 \mathrm{~s}$ & -37.6 & 131.7 & No & & $2000 \mathrm{~s}$ & -53.0 & 176.4 & No \\
\hline & $2010 \mathrm{~s}$ & -40.3 & 144.6 & & & $2010 \mathrm{~s}$ & -0.4 & 200.5 & \\
\hline \multirow{4}{*}{ Negro } & $1980 \mathrm{~s}$ & -59.9 & 107.6 & Significant & \multirow{4}{*}{ Xingu } & $1980 \mathrm{~s}$ & 25.5 & 183.6 & No \\
\hline & 1990s & 16.5 & 139.3 & Significant & & $1990 \mathrm{~s}$ & 4.7 & 186.1 & No \\
\hline & $2000 \mathrm{~s}$ & 61.0 & 140.8 & Significant & & $2000 \mathrm{~s}$ & -28.2 & 184.7 & No \\
\hline & $2010 \mathrm{~s}$ & -15.6 & 116.7 & & & $2010 \mathrm{~s}$ & -18.7 & 203.5 & \\
\hline \multirow{4}{*}{ Purus } & $1980 \mathrm{~s}$ & -5.6 & 200.6 & No & & & & & \\
\hline & $1990 \mathrm{~s}$ & -13.2 & 201.7 & No & & & & & \\
\hline & $2000 \mathrm{~s}$ & 18.0 & 216.6 & No & & & & & \\
\hline & $2010 \mathrm{~s}$ & 6.2 & 235.1 & & & & & & \\
\hline
\end{tabular}




\section{TWS Deficit and Release Variations between Drought Years}

We define the dry season total water deficit (TWD) as the cumulative difference between monthly potential evapotranspiration (PET) and precipitation (P) for the period during which $\mathrm{P}<\mathrm{PET}$. The corresponding drop in the simulated TWS, during the same period as of TWD, is defined as the TWS release (TWS-R).

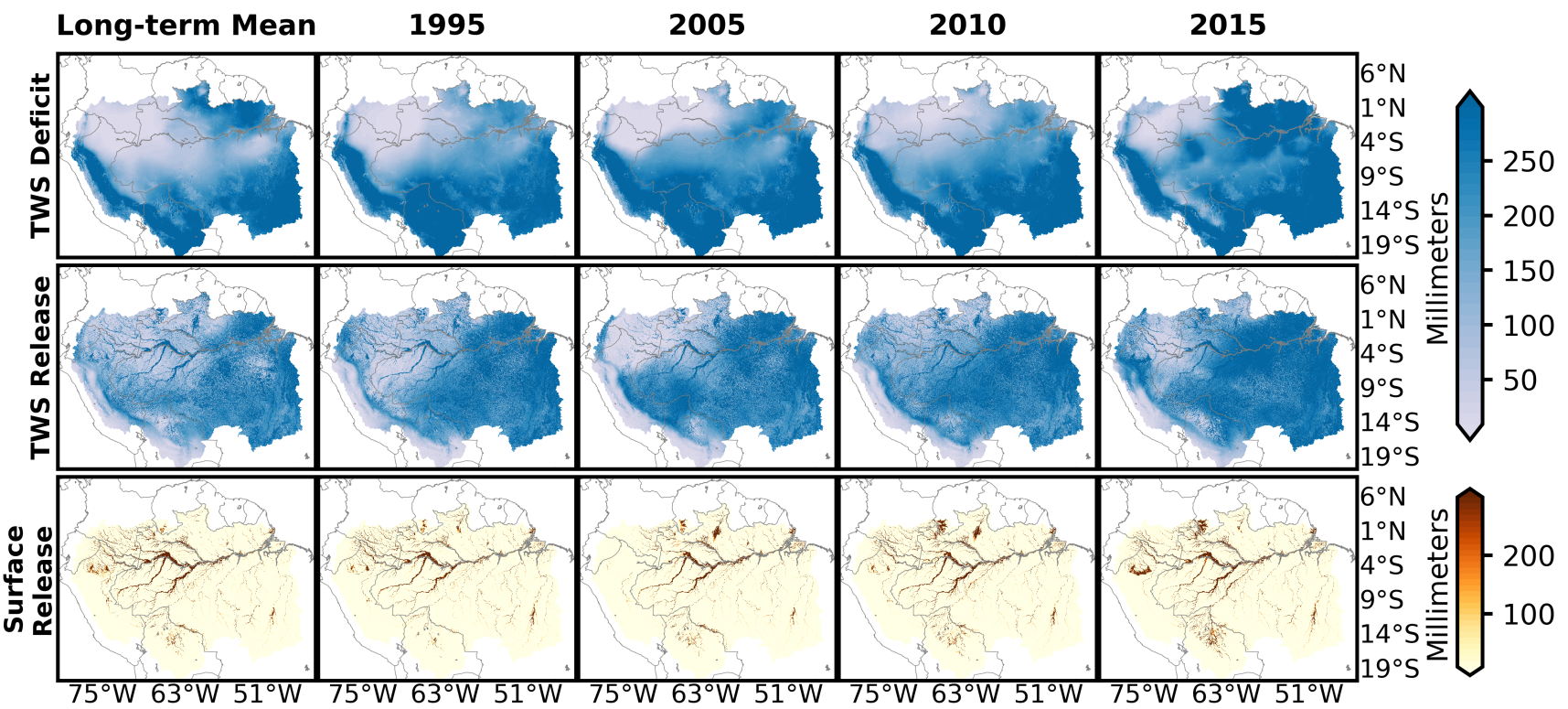

Figure S10 - Spatial comparison of TWD quantified as the cumulative PET-P, the corresponding simulated TWS-R from LHF and the contribution of surface water to the total TWS-R for the extreme drought years, at original $\sim 2 \mathrm{~km}$ model grids. Long-term mean is 1980-2015 mean. Note that the ranges of colour bars differ among the plots. 


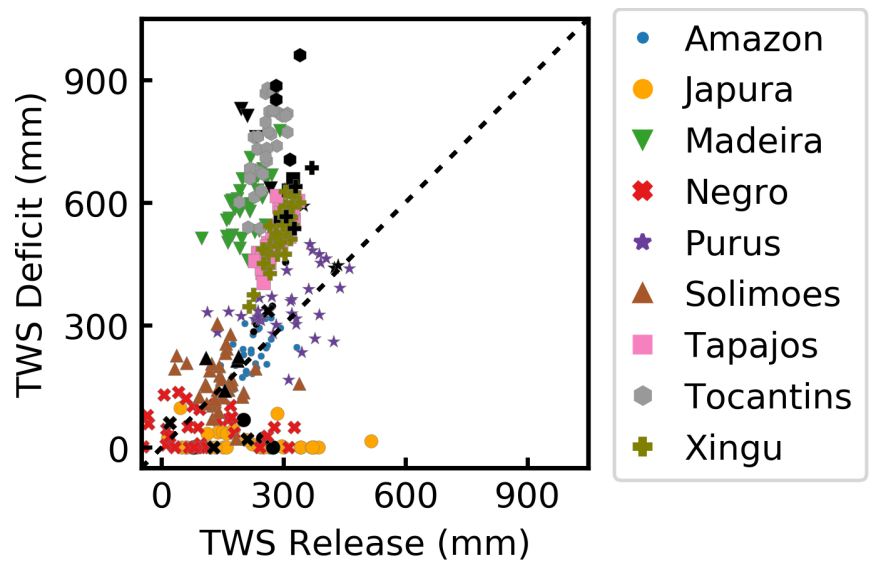

Figure S11 - Relationship between annual TWD and TWS-R for the period of 1980-2015, colour coded by Amazonian sub-basins. Points for extreme drought events are highlighted in black. Each marker type represents different river basins, totalling 36 markers for each river basin for the period of 1980-2015. Black dashed line indicates 1:1 relationship between TWD and TWS-R.

\section{References}

Miguez-Macho, G. and Fan, Y.: The role of groundwater in the Amazon water cycle: 2. Influence on seasonal soil moisture and evapotranspiration, J. Geophys. Res. Atmos., 117(15), doi:10.1029/2012JD017540, 2012.

Scanlon, B. R., Zhang, Z., Save, H., Sun, A. Y., Müller Schmied, H., van Beek, L. P. H., Wiese, D. N., Wada, Y., Long, D.,

10 Reedy, R. C., Longuevergne, L., Döll, P. and Bierkens, M. F. P.: Global models underestimate large decadal declining and rising water storage trends relative to GRACE satellite data, Proc. Natl. Acad. Sci., 201704665, doi:10.1073/pnas.1704665115, 2018.

Sun, A. Y., Scanlon, B. R., Zhang, Z., Walling, D., Bhanja, S. N., Mukherjee, A. and Zhong, Z.: Combining Physically-Based Modeling and Deep Learning for Fusing GRACE Satellite Data: Can We Learn from Mismatch?, Water Resour. Res., 0(ja), 15 doi:10.1029/2018WR023333, 2019. 